\title{
PAIS SEPARADOS E FILHOS: ANÁLISE FUNCIONAL DAS DIFICULDADES DE RELACIONAMENTO'
}

\author{
SEPARATED PARENTS AND CHILDREN: FUNCTIONAL ANALYSIS OF \\ BEHAVIOR DIFFICULTIES
}

\author{
Profa. Dra. Carmen Garcia de ALMEIDA ${ }^{2}$ \\ Ednéia Aparecida PERES ${ }^{3}$ \\ Marcos Roberto GARCIA ${ }^{4}$ \\ Nadya Christiane Silveira PELLIZZAR ${ }^{5}$
}

\begin{abstract}
RESUMO
Estudos realizados revelam que a separação conjugal pode exercer efeitos negativos sobre o relacionamento entre pais e filhos. A forma como os pais se relacionam com os filhos e entre si interfere na maneira positiva ou negativa de ofilho enfrentara separação. Este trabalho teve como objetivosidentificar dificuldades de relacionamento vivenciadas por pais e filhos e analisar as variáveis das quais estas dificuldades eram função, além de promover a interação entre eles. Os participantes foram 3 pais e 3 crianças, com idades entre 29 a 41 anos e 8 a 12 anos, respectivamente. O trabalho realizado na Clínica Psicológica da UEL consistiu de 36 encontros, sendo 11 comos pais, 11 com os filhose 14 conjuntos. As intervenções consistiram de: desenhos, pinturas, orientações sobre disciplina, treino em expressividade emocional, dentre outras. A avaliação inicial das dificuldades revelou a existência de comportamentos agressivos e inassertivos dos pais, sendo que os filhos tambémapresentaram dificuldadessemelhantes. Os resultados daintervençãoapontaram melhoras nos comportamentos de imaturidade e isolamento dos filhos e na expressão de sentimentos de pais e filhos. Embora tenham ocorrido mudanças comportamentais, sugerem-se intervenções futuras envolvendo pais que não estão com a guarda dos filhos, os quais contribuem para as dificuldades de relacionamento por eles apresentadas
\end{abstract}

(1) O presente trabalho resultou da pesquisa de Pós-Doutorado realizada pela Profa. Dra. Carmen Garcia de Almeida, apresentada ao Instituto de Psicologia da Universidade de São Paulo em fevereiro de 1997, sob a orientação da Profa. Dra. Edwiges Ferreira Mattos Silvares, com apoio financeiro do CNPq.

(2) Universidade Estadual de Londrina Av. Voluntários da Pátria, 674 Jardim Andrade - Londrina - Paraná - CEP 86061 -080 E-mail:carmen@sercomtel.com.br. FAX: (043) 371-4207

(3) Estagiária bolsista CNPq/UEL,UEM - UEL.

(4) Bolsista de aperfeiçoamento CNPq - UEL.

(5) Estudante de Especialização - UEL. 
Palavras-chave: separação conjugal; relacionamento entre pais e filhos; análise funcional

\begin{abstract}
Studies reveal that the legal separation can exert negative effects on the relationship between parents and children. The way parents relate with their children as well as between themselves, interferes in the positive ornegative way the child deals with the separation. The purposes of this work were to identify the relationship difficulties experienced by parents and children and to analyse the variables which generated these difficulties, besides promoting the interaction between them. The participants were three parents and three children, with ages ranging from 29 to 41 years old and 8 to 12 years old, respectively. The work performed at the University's Psychological Clinic consisted of 36 meetings: 11 with the parents, 11 with the children and 14 with both parents and children. The interventions consisted of:drawings, paintings, orientations about discipline, training in emotional expressiveness, among others. The initial evaluation of the difficulties revealed the existence of agressive and unassertive behaviors on the part of the parents. The children also presented similar difficulties. The results of the intervention showed improvements in the immaturity and isolation behaviors on the part of the children as well as in the expression of feelings on both parts. Although behavioral changes have happened, future interventions are suggested, involving parents who do not have the custody of the children, whocontribute for the difficulties of the relationship presented by them.
\end{abstract}

Key words: legal separation; relationship between parents and children; functional analysis.

\section{INTRODUÇÃO}

A separação conjugal vem se multiplicando consideravelmente na atualidade, podendo acarretar diversas conseqüências aos envolvidos, como, por exemplo, situações estressantes. "O estresse se refere a um desgaste geral do organismo, cansado pelas alterações psicofisiológicas que se dão quando a pessoa se vê forçada a enfrentar uma situação que a irrite, amedronte, confunda, excite, ou que a faça muito feliz" (Lipp \& Malagris, 1995, p. 179).

De acordo com Tschann et al. (1989) o divórcio acarreta mudanças que geram estresse nos relacionamentos familiares, as quais interferem no ajustamento das crianças e podem alterar as etapas normais de seu desenvolvimento. $\mathrm{O}$ bem-estar emocional das crianças e sua adaptação social são os mais afetados pela experiência do divórcio. Alguns dos principais causadores do stress, em caso de divórcio, referem-se ao conflito conjugal tanto antes como depois da separação, ao relacionamento problemático com um ou ambos os pais e à perda de contato ou diminuição do mesmo com um dos pais, geralmente com o pai. De acordo com alguns pesquisadores, as crianças costumam responder a estas experiências estressoras de formas variadas, dependendo de suas características individuais.

O estresse vivenciado pelos filhos parece estar relacionado diretamente com o estresse dos pais e os contatos negativos entre eles, é inversamente relacionado ao tempo transcorrido desde a separação. 
O medo de perder o contato com o pai, que está indo embora, é o principal desajuste causa do pelo divórcio. As conseqüências emocionais advindas dessa situação, para os filhos, como depressão, raiva, ansiedade e isolamento, são bem severas, conforme colocam Hess e Câmara (1979).

Os resultados de pesquisa de Câmara e Desnick (apud Moraes, 1997) indicam que quando há cooperação entre os pais, o ajustamento social de seus filhos se estabiliza por volta de 2 anos após o divórcio.

A forma como os pais se relacionam com os filhos e entre si interfere na maneira positiva ou negativa de o filho enfrentar a separação. Se os pais se agridem constantemente, as crianças podem considerar este comportamento como adequado e passam a emití-lo no relacionamento com os outros.

Os momentos subseqüentes à separação são os mais difíceis, tanto para os pais como para os filhos. Sendo assim, não se deve esperar que lidem de forma satisfatória com as conseqüências sociais, financeiras e emocionais, ligadas à dissociação do casamento, pois necessitam de um tempo para se reconstruírem.

Outro fator de extrema importância se refere à ausência de um dos cônjuges na vida dos filhos. Esta ausência pode influenciar a percepção do mundo e de si mesmo, contribuindo para uma auto-imagem ruim, apresentando níveis alto de ansiedade, desenvolvimento afetivo instável, dificuldades para controlar a agressividade, impulsividade e aparecimento de comportamentos depressivos.

Tanto as crianças como os adolescentes poderão reagir de forma diferente diante de uma mesma situação. Diante do divórcio, muitos filhos não apresentam problemas de ordem comportamental, enquanto outros os apresentam.

\section{Conforme Teybere Hoffman(1987):}

"Um dos mais fortes determinantes do ajustamento dos filhos ao divórcio é a extensão da participação continuada dos pais em suas vidas. Os filhos do divórcio sofrem social, emocional e intelectualmente quando seus pais não estão ativamente envolvidos com seu papel. Eles parecem culpar-se pela partida dos pais e sofrem uma perda da auto-estima e iniciativa, perda esta refletida na depressão, desempenho acadêmico pobre e falhas nos relacionamentos interpessoais. Os filhos do divórcio melhor ajustados são os que têm freqüentemente acesso, sem conflitos, a pai e mãe."(apud Moraes et al., 1997,p. 17)

Quanto ao impacto da separação sobre os cônjuges, Kaslow e Schwartz (1995) colocam que a maioria dos divorciados recentes permanecem inibidos, deprimidos, amargurados e preocupados com os filhos, emprego ou dinheiro. Alguns se encontram cansados, aliviados ou confusos, podendo ainda ter esses três sentimentos ao mesmo tempo,já que a ambivalência é normal nesse caso.

Há pontos em comum vivenciados pelos divorciados: as etapas do processo de separação; a necessidade de sobrevivência e o desenvolvimento de novos estilos de vida e autoimagem; mudanças quanto ao fator econômico e crises emocionais que muitos enfrentam.

O período que se segue ao divórcio legal, para algumas pessoas, é uma "exploração do seu mundo privado (sentimentos, pensamentos, emoções), assim também do ambiente externo (tentando novas atividades, retomando antigos projetos, construindo novos relacionamentos sociais)" (Kaslow e Schwartz, 1995, p. 53) . Nesse momento a terapia individual ou de grupo pode proporcionar o desenvolvimento de valores e de estruturas que irão permear a vida delas, bem como ajudá-las a exercer bem seus múltiplos papéis sociais (pai, mãe, amigo, ajudante nas lições de casa, trabalhador, estudante e a desfrutar de todas as oportunidades que a vida pode-lhes oferecer).

Como são muitas as alterações sofridas pelos filhos diante da separação, Giusti, 1987 
(apud Moraes et al., 1997) referindo-se às opções úteis que poderiam ajudá-los a superar esse período, propõe a busca de um especialista. Concordando com isso, Maldonado (1978) coloca que é importante para a criança ter um espaço para expressar seus sentimentos, dúvidas, emoções acerca da separação dos pais e do relacionamento com os mesmos.

Para Kaslow e Schwartz (1995, p. 51) "os filhos parecem ficar "abandonados" na época da separação, quando a energia dos pais está voltada para a mesma,sem haver então dedicação aos filhos". Porém, há outros pais que tentam superproteger os filhos, pensando que assim eles não sofrem. Nesse momento, a terapia de grupo pode ajudar os filhos a lidar bem com esta situação. A constatação de que outras crianças enfrentam a mesma realidade do divórcio, a expressão de sentimentos, dúvidas, angústias e o levantamento de alternativas adequadas para superar este período difícil, são pontos relevantes na terapia grupal.

As intervenções grupais realizadas basearam-se na Análise Funcional dos Comportamentos, o que, segundo Meyer (1997) consiste na análise das variáveis das quais o comportamento é função.

Assim, este trabalho teve como objetivos identificar dificuldades de relacionamento vivenciadas por pais e filhos e analisar as variáveis das quais estas dificuldades eram função, além de promover a interação entre eles.

\section{METODOLOGIA}

Os encontros foram realizados na Clínica Psicológica da UEL, durante o período de maio a novembro de 1997, consistindo de atendimentos semanais, com duração aproximada de uma hora e vinte minutos.

A população selecionada por um roteiro de entrevistas de triagem com os pais consistiu de 6 participantes, 3 pais ( 1 pai e 2 mães) e 3 filhos (3 meninos), com idades variando entre 28 e 41 anos e 08 e 13 anos, respectivamente.

Para facilitar a visualização, será apresentada uma tabela com a caracterização dos sujeitos.

Foi realizado um total de 36 encontros, sendo 11 com os pais, 11 com os filhos e $14 \mathrm{em}$ conjunto (pais e filhos).

Para os atendimentos foram utilizados colchonetes para relaxamento, papel jornal, sulfite, lápis colorido, giz de cera, revista, cola, tesoura e canetas hidrocolores como também atividades lúdicas para o levantamento de comportamentos relevantes na interação pais e filhos.

Nos atendimentos foram igualmente utilizados instrumentos de avaliação comportamental aplicados em pais e filhos, no início e no término do trabalho. Tais instrumentos foram: Questionário para Análise Comportamental da Relação Pais/Filhos, segundo a percepção dos filhos; Questionário para Análise Comportamental da Relação Pais/Filhos, segundo a percepção dos

\begin{tabular}{|c|c|c|c|c|c|c|c|}
\hline $\begin{array}{c}\text { Identificaçāo } \\
\text { do sujeito }\end{array}$ & Sujeito & Idade & Sexo & $\begin{array}{c}\text { Identificação } \\
\text { do sujeito }\end{array}$ & Sujeito & Idade & Sexo \\
\hline S. & Māe & 28 & Feminino & L. & Criança & 8 & Masculino \\
\hline T. & Mãe & 38 & Feminino & E. & Criança & 10 & Masculino \\
\hline C. & Pai & 41 & Masculino & D. & Criança & 13 & Masculino \\
\hline
\end{tabular}

S. corresponde à mãe de $\mathrm{L}$.

$T$. corresponde à mãe de $E$.

C. corresponde ao pai de D. 
pais; Questionário de Identificação de Comportamentos-Problema - Walkker - Checklist; r elatório dos pais; Questionário brasileiro para investigação de Autoconceito para crianças, de Amaral et al. (em anexo).

O procedimento utilizado para a formação do grupo, inicialmente, consistiu no recrutamento dos participantes através de meios de comunicação de massa (jomal e rádio).

Os critérios para a seleção dos participantes do grupo foram: a idade dos filhos (entre $8 \mathrm{e}$ 12 anos), a existência de comportamentos-problema relacionados à separação dos pais e a disponibilidade de horários.

Na seqüência, iniciaram-se os encontros, em que os participantes responderam aos questionários de Análise Comportamental da Relação Pais/Filhos (que foi especialmente estruturado para um trabalho desta natureza), questionário para a investigação do Autoconceito nas crianças, e o questionário para Identificação de Comportamentos- Problema -Walker.

Os encontros com os pais foram conduzidos pelos estagiários vinculados ao projeto de pesquisa e os encontros com os filhos, pelas alunas do Curso de Especialização, sendo que, os encontros eram realizados, quinzenalmente, com os pais e filhos conjuntamente.

Inicialmente procurou-se levantar a história do relacionamento entre o participante e seu ex-cônjuge, os dados sobre o processo da separação e sobre o relacionamento afetivo atual dos participantes, bem como identificar comportamentos relevantes dos pais que pudessem estar mantendo comportamentos inadequados dos filhos. Estes comportamentos se referiam à utilização dos filhos para agredir o ex-cônjuge, à coerção, à insatisfação pela condição da separação, bem como à indefinição da relação com o ex-cônjuge.

No decorrer dos encontros, a Análise Funcional dos Comportamentos apresentados pelos pais possibilitou-Ihes compreenderem que estariam influenciando os com-portamentos-queixa dos filhos, e assim facilitou a discriminação dos mesmos quanto à funcionalidade de seus comportamentos.

Nos encontros com os pais foram utilizadasalgumas estratégias, tais como: desenhos, atividades lúdicas, trocas de experiências e relatos verbais enfocando a condição da separação a relação com o ex-cônjuge, o relacionamento familiar e o relacionamento afetivo com outros parceiros.

Nas intervenções conjuntas, foram utilizadas técnicas de dinâmica de grupo, as quais consistiram na elaboração de perguntas feitas pelos coordenadores, para que tanto os pais quanto os filhos pudessem respondê-las, tentando acertar o que o outro (pai ou filho) responderia e em atividades lúdicas em pares, como desenhos e brincadeiras, objetivando verificar as interações entre eles.

Além das dinâmicas de grupo, foram realizadas atividades em que os coordenadores propiciavam a expressividade de sentimentos entre pais e filhos com o objetivo de verificar como um percebia o outro em relação aos gostos, qualidades e defeitos.

\section{RESULTADOS}

Emseguida seráapresentado um perfil dos participantes do grupo (pais e filhos), elaborado a partir das informações obtidas nas entrevistas de triagem, das aplicações dos instrumentos de avaliação e das percepções dos terapeutas du-rante a realização dos encontros.

No quadro 1 as respostas dos pais (S., T. eC.) na etapa de pré intervenção, em relação aos seus relacionamentos com os filhos é considerado por eles como boa, com irritabilidade com os filhos, boa e regular, respectivamente. $\mathrm{Na}$ etapa de pós intervenção as respostas foram: regular e bom.

Quanto as respostas dos filhos (L.,E.e D.) no período de pré intervenção foram: ótimo e regular, já na etapa de pós intervenção as respostas foram: bom, ótimo e regular. 
Quadro 1. Aspectos comportamentais dos sujeitos referentes ao "relacionamento atual entre pais e filhos." (")

\begin{tabular}{|c|l|l|}
\hline SUJEITOS & $\begin{array}{l}\text { COMPORTAMENTOS } \\
\text { PRÉ-INTERVENÇĀO }\end{array}$ & $\begin{array}{l}\text { COMPORTAMENTOS } \\
\text { PÓS-INTERVENÇÃO }\end{array}$ \\
\hline S. & $\begin{array}{c}\text { - Bom } \\
\text { - Irritabilidade com os filhos }\end{array}$ & - Bogular \\
\hline L. & - Ótimo & $\bullet$ Bom \\
\hline T. & - Bom & Ótimo \\
\hline E. & - Ótimo & Bom \\
\hline C. & - Regular & - Regular \\
\hline D. & Regular & \\
\hline
\end{tabular}

() Dados coletados dos instrumentos e das verbalizaçóes dos encontros.

No quadro 2, a percepção dos pais (S., T. e C.), referente aos aspectos positivos e negativos da separação, no período de pré intervenção, contém respostas que oscilaram do positivo para o negativo. Para a participante S. a separação foi negativa, enquanto que para T. foi positivo, no entanto diminuiu a renda familiar (negativo). Para C. a separação trouxe benefícios. Já no período de pós intervenção a participante $\mathrm{S}$. percebeu aspectos positivos da separação (menos dependência do ex-marido). Para T. a participação no grupo a ajudou a repensar em seu relacionamento, e tentou estabelecer uma relação amigável com o ex marido (positivo). C. percebeu-se mais tolerante em relação à ex cônjuge, mas estava com dificuldade em seu novo relacionamento.

Para os filhos (L., E.e D.) no período de pré intervenção a separação dos pais para todos foi negativa, alterando alimentação, aumentando a agressividade, dificultando os novos relacionamentos dos pais, além das dificuldades em manter um bom relacionamento com o pai que detém a guarda. No período da pós intervenção, L. e E. continuaram sentindo a falta dos pais. Para D. neste período percebeu-se mais comunicativo com o pai, porém, continuou com dificuldades em aceitar o relacionamento do pai, apresentava dores de cabeça e seu peso aumentou.
No quadro 3 as respostas dos pais (S., T. e C.), referentes ao relacionamento com o ex cônjuge no período de pré intervenção, apareceram de formas variadas. S. no início do trabalho tentou resgatar o casamento desfeito; a participante T. omitia os comportamentos do filho para o ex marido, excluindo-o das condutas do filho, no entanto mantinha uma relação afetiva instável com o ex marido. O relacionamento de C. com a ex mulher pautava-se também na exclusão dela frente a responsabilidade dos filhos, e rejeitava a idéia de D. irmorar coma mãe. No período de pós intervenção S. percebeu o que a fazia sentir-se insatisfeita e do porquê usava os filhos para atingir o ex marido. T. deu maior abertura ao ex cônjuge em relação aos filhos; e C. aceitou a condição de $\mathrm{D}$. morar com a mãe, além de diminuir a freqüência de falar da ex mulher, passando a falar de seu relacionamento atual.

Para a criança L., no início do grupo, seu relacionamento com o pai era ótimo, pois tinha a presença deste. Para E. era considerado bom e para D. ótimo. Após a intervenção L. avaliava a situação (relacionamento com o pai) como boa, pois o pai, neste momento, já não estava mais presente. Para E. passou a ser ruim a medida em que foi percebendo a ausência do pai. D. avaliou a situação como sendo ótimo, mesmo após ter ido morar com a mãe, e relatado que a experiência não havia sido boa. 
Quadro 2. Aspectos comportamentais dos sujeitos referentes aos "aspectos positivos e negativos da separaçāo." (")

\begin{tabular}{|c|c|c|}
\hline SUJEITOS & $\begin{array}{l}\text { COMPORTAMENTOS } \\
\text { PRÉ-INTERVENÇÄO }\end{array}$ & $\begin{array}{l}\text { COMPORTAMENTOS } \\
\text { POS-INTERVENÇĀO }\end{array}$ \\
\hline $\mathrm{S}$ & $\begin{array}{l}\text { - Dificuldades emaceitar a separaçăo } \\
\text { (negativo) } \\
\text { - Dependência em relação ao ex- } \\
\text { marido (negativo) }\end{array}$ & $\begin{array}{l}\text { - Menos dependente do ex-marido } \\
\text { (positivo) }\end{array}$ \\
\hline L. & $\begin{array}{l}\text { - Separação considerada ruim pela } \\
\text { ausência do pai (negativo) } \\
\text { - Alteração naalimentação (negativo) }\end{array}$ & $\begin{array}{l}\text { - Separação considerada ruim pela } \\
\text { ausência do pai (negativo) }\end{array}$ \\
\hline T. & $\begin{array}{l}\text { - Diminuição das brigas (positivo) } \\
\text { - Diminuição da renda familiar } \\
\text { (negativo) }\end{array}$ & $\begin{array}{l}\text { - Tentativa de estabelecer um relaciona- } \\
\text { mento amigável com o excônjuge (posi- } \\
\text { tivo) }\end{array}$ \\
\hline E. & $\begin{array}{l}\text { - Separação considerada negativa } \\
\text { pela ausência da pai e positiva pela } \\
\text { diminuição das brigas entre os pais } \\
\text { (negativo) } \\
\text { - Agressividade com os irmãos } \\
\text { (negativo) } \\
\text { - Irritabilidade sem motivo aparente } \\
\text { (negativo) }\end{array}$ & - Sente a ausência do pai (negativo) \\
\hline C. & $\begin{array}{l}\text { - Diminuiçāo de conflitos (positivo) } \\
\text { - Aumento da renda familiar (positivo) } \\
\text { - Novo relacionamento afetivo } \\
\text { (positivo) }\end{array}$ & $\begin{array}{l}\text { - Dificuldades no novo relacionamento } \\
\text { afetivo (negativo) } \\
\text { - Maior tolerância em relação à excônjuge } \\
\text { (positivo) }\end{array}$ \\
\hline D. & $\begin{array}{l}\text { - Sente falta da măe (negativo) } \\
\text { - Dificuldade de relacionamento com } \\
\text { o pai (negativo) } \\
\text { - Dificuldade em aceitar o novo } \\
\text { relacionamento do pai (negativo) }\end{array}$ & $\begin{array}{l}\text { - Maior diálogo com o pai (positivo) } \\
\text { - Dificuldade em aceitar o novo relaciona- } \\
\text { mento do pai (negativo) } \\
\text { - Dores de cabeça (negativo) } \\
\text { - Aumento do apetite (negativo) }\end{array}$ \\
\hline
\end{tabular}

(") Dados coletados dos instrumentos e das verbalizaçōes dos encontros.

O quadro 4 contém respostas referentes ao relacionamento social dos participantes. As respostas no período de pré intervenção, a participante $\mathrm{S}$. mantinha relacionamentos inassertivos e agressivos, assim como a participante T. mantinha relacionamentos também agressivos com postura impositiva e o participante $\mathrm{C}$. racional, monopolizador e agressivo.

No quadro 5 , referente a auto-imagem, o grupo dos pais, no período de pré intervenção, pode-se perceber que a participante S. via-se incapaz de realizar atividades por si própria, além de aparentar desinteresse por outros parceiros. A participante T., neste mesmo período, apresentava falta de cuidados em relação à sua aparência, e C. considerava-se correto, sábio e perfeccionista. No período de pós intervenção a participante $\mathrm{S}$. já estava realizando atividades que antes não acreditava realizar e começava a se interessar por outros homens. A participante 
T. começou a se cuidar mais quanto a sua aparência e o participante $\mathrm{C}$. começou a perceber e aceitar as suas falhas.

No início do grupo das crianças o participante L. considerava-se "burro" e "feio". Já o participante $\mathrm{E}$. apresentou um alto auto conceito e o participante $D$. apresentava-se pessimista e considerava-se incapaz de realizar tarefas difíceis. No final do grupo L. já havia diminuído as verbalizações auto depreciativas; o participante E. apresentou um médio auto conceito e o participante D. aumentou sua confiança em si mesmo.

No quadro 6, o qual mediu o desempenho acadêmico, o grupo dos pais no período de pré intervenção, a participante $\mathrm{S}$. tinha curso profissionalizante de cabeleireira e cursava o curso de Letras na Universidade Estadual de Londrina, apesar de estar insatisfeita com ele. T. também tinha curso profissionalizante (manicure), exigia boas notas dos filhos e apresentavase muito preocupada com a freqüência de $E$. na escola. O participante C. era doutor, professor na Universidade, e apresentava-se disciplinado e exigente em relação aos seus estudos. No período de pós intervenção $S$. passou a valorizar mais o curso que vinha fazendo. T. percebeu as causas que mantinham o comportamento de $\mathrm{E}$. não ir à escola, e C. não apresentou mudanças.

No início do grupo dos filhos, L. apresentava boas notas (pai estava presente neste período) e fazia aulas de Kumon, o participante E.

Quadro 3. Aspectos comportamentais dos sujeitos referentes aos "relacionamento com o ex-cónjuge que mantém a guarda do tilho."(")

\begin{tabular}{|c|c|c|}
\hline SUJEITOS & $\begin{array}{l}\text { COMPORTAMENTOS } \\
\text { PRÉ-INTERVENÇĀOO }\end{array}$ & $\begin{array}{l}\text { COMPORTAMENTOS } \\
\text { POS-INTERVENCZÄOO }\end{array}$ \\
\hline S. & $\begin{array}{l}\text { - Tentativa de resgate do casamento, } \\
\text { dizendo que ainda amava o ex- } \\
\text { cônjuge }\end{array}$ & $\begin{array}{l}\text { - Percepçăo de sua insatisfação quanto à } \\
\text { condiçăo de separada, e de usar os } \\
\text { filhos para atingir o ex-cônjuge }\end{array}$ \\
\hline L. & $\begin{array}{l}\text { - Ótimo } \\
\text { - Tem a presença do paí }\end{array}$ & $\begin{array}{l}\text { - Bom } \\
\text { - Ausência do pai }\end{array}$ \\
\hline T. & $\begin{array}{l}\text { - Omissão dos comportamentos do } \\
\text { filho para o ex-cônjuge } \\
\text { - Excluia o ex-cônjuge de respon- } \\
\text { sabilidades em relação ao filho } \\
\text { - Relação afetiva instável entre os } \\
\text { cônjuges }\end{array}$ & $\begin{array}{l}\text { - Maior abertura com o ex-cônjuge em } \\
\text { relaçăo aos filhos }\end{array}$ \\
\hline E. & - Bom & $\begin{array}{l}\text { - Ruim } \\
\text { - Percepção da ausência do pai }\end{array}$ \\
\hline C. & $\begin{array}{l}\text { - Exclusão do ex-cônjuge quanto à } \\
\text { responsabilidade dos filhos } \\
\text { - Inflexibilidade quanto ao filho morar } \\
\text { com a mãe }\end{array}$ & $\begin{array}{l}\text { - Aceitação da condição do filho morar } \\
\text { com a mãe } \\
\text { - Diminuição da frequeência de falar da ex- } \\
\text { mulher, passando a falar mais de seu } \\
\text { relacionamento atual }\end{array}$ \\
\hline D. & - Ótimo & $\begin{array}{l}\text { - Otimo } \\
\text { - Experienciou morar com a mãe e optou } \\
\text { em continuar morando com o pai }\end{array}$ \\
\hline
\end{tabular}

(") Dados coletados dos instrumentos e das verbalizaçర̄es dos encontros. 
gostava de estudar, mas não queria ir à escola, sendo quejáestava reprovando, eD. apresentava notas baixas e suspeitava que iria reprovar, além das inúmeras queixas que tinha da escola. No final do período de intervenção, L. apresentou notas baixas (período em que o pai se ausentou), e D. começou a se esforçar para tirar notas altas o que resultou na aprovação do ano letivo.

Quadro 4. Aspectos comportamentais dos sujeitos referentes aos "relacionamento social."(")

\begin{tabular}{|c|c|c|}
\hline SUJEITOS & $\begin{array}{l}\text { COMPORTAMENTOS } \\
\text { PRÉ-INTERVENÇĀOO }\end{array}$ & $\begin{array}{l}\text { COMPORTAMENTOS } \\
\text { PÓS-INTERVENÇÃOO }\end{array}$ \\
\hline $\mathrm{S}$. & - Inassertividade e agressividade & $\begin{array}{l}\text { - Início da discriminação das causas da } \\
\text { irritabilidade } \\
\text { - Melhor aceitação de feedback } \\
\text { - Aumento de atividades de lazer, como } \\
\text { passeios à noite }\end{array}$ \\
\hline L. & $\begin{array}{l}\text { - Isolamento } \\
\text { - Dificuldade em realizar atividades } \\
\text { em grupo } \\
\text { - Dificuldade em aceitar elogios }\end{array}$ & $\begin{array}{l}\text { - Maior envolvimento em atividades } \\
\text { grupais } \\
\text { - Aceitação de feedbacks dados pelos } \\
\text { participantes do grupo }\end{array}$ \\
\hline T. & $\begin{array}{l}\text { - Agressividade } \\
\text { - Imposição }\end{array}$ & - Maior receptividade a opinióes \\
\hline E. & - Paticipativo & - Isolamento \\
\hline C. & $\begin{array}{l}\text { - Racional } \\
\text { - Monopolizador } \\
\text { - Agressivo }\end{array}$ & $\begin{array}{l}\text { - Flexivel na aceitaçâo de feedbacks } \\
\text { - Reflexivo frente às questōes que envol- } \\
\text { vem sentimentos }\end{array}$ \\
\hline D. & $\begin{array}{l}\text { - Desprezo frente à situaçōes que } \\
\text { envolviam demonstração de } \\
\text { sentimentos } \\
\text { - Agressividade com os membros } \\
\text { do grupo } \\
\text { - Fantasia de situaçăo em que } \\
\text { obtinha sucesso }\end{array}$ & $\begin{array}{l}\text { - Maior expressão de sentimentos } \\
\text { - Diminuição da agressividade } \\
\text { - Relatos de fatos concretos }\end{array}$ \\
\hline
\end{tabular}

(") Dados coletados dos instrumentos e das verbalizaçōes dos encontros.

\section{DISCUSSÃO}

De acordo com a literatura consultada, encontramos que o processo de separação é uma situação estressante tanto para os pais quanto para os filhos. Nota-se que algumas pessoas lidam melhor com ela, enquanto outras encontram maiores dificuldades em enfrentá-la.

Dentre as conseqüências negativas da separação comumente encontradas temos a queda no rendimento escolar e as dificuldades de relacionamento interpessoal. Corroborando esta idéia temos Grych \& Fincham (1990) que enfatizam em seus estudos os efeitos negativos trazidos pelos conflitos conjugais presentes antes e depois da separação. Relatam ainda esses autores que as crianças de famílias caracterizadas por alto grau de conflito apresentam maior desajustamento, do que aquelas caracterizadas por baixo grau de conflito. 
Quadro 5. Aspectos comportamentais dos sujeitos referentes a "auto-imagem."(*)

\begin{tabular}{|c|c|c|}
\hline SUJEITOS & $\begin{array}{l}\text { COMPORTAMENTOS } \\
\text { PRÉ-INTERVENÇÃOO }\end{array}$ & $\begin{array}{l}\text { COMPORTAMENTOS } \\
\text { PÓS-INTERVENÇÃO }\end{array}$ \\
\hline S. & $\begin{array}{l}\text { - Incapaz de realizar atividades por si } \\
\text { própria } \\
\text { - Desinteresse por outros parceiros }\end{array}$ & $\begin{array}{l}\text { - Realizaçăo de atividades que antes } \\
\text { acreditava năo conseguir, como dirigir } \\
\text { um carro } \\
\text { - Início de novos relacionamentos }\end{array}$ \\
\hline L. & $\begin{array}{l}\text { - Verbalizações auto-depreciativas } \\
\text { (dizia ser burro e feio) }\end{array}$ & $\begin{array}{l}\text { - Diminuição das verbalizações de } \\
\text { auto-depreciaçāo }\end{array}$ \\
\hline T. & $\begin{array}{l}\text { - Falta de cuidados pessoais (apa- } \\
\text { rência) }\end{array}$ & - Melhora da aparência \\
\hline E. & - Alto auto-conceito & - Médio auto-conceito \\
\hline C. & $\begin{array}{l}\text { - Considera-se correto e sábio } \\
\text { - Perfeccionista }\end{array}$ & - Percepção e aceitação de suas falhas \\
\hline D. & $\begin{array}{l}\text { - Pessimista, considerava-se inca- } \\
\text { paz de realizartarefas dificeis, como } \\
\text { passar de ano }\end{array}$ & - Maior auto-confiança \\
\hline
\end{tabular}

(") Dados coletados dos instrumentos $\mathrm{e}$ das verbalizaçōes dos encontros.

Maldonado (1987) também acentua que o processo de separação pode exercer efeitos negativos sobre os comportamentos dos filhos. Um desses efeitos freqüentemente observado são as acusações recíprocas entre os cônjuges, gerando um alto grau de conflito. Este tipo de conduta acaba, na maioria das vezes, por fazer com que os filhos se sintam culpados ou responsáveis pela separação.

Com o decorrer das intervenções junto ao grupo de pais, percebeu-se, que principalmente para a participante $S$, houve dificuldades quanto à aceitação da separação por ela depender do marido, financeira e emocionalmente, o qual contribuía para que ela não tomasse decisões em relação à sua vida profissional e familiar. Para os demais membros do grupo, a separação acarretou na diminuição de brigas e conflitos, oportunizando novos relacionamentos, conforme foi relatado por eles durante os encontros.

Kaslow e Schwartz (1995), reconhecem que a separação causa mudanças nos divorciados, as quais interferem em seus comportamen- tos privados (sentimentos, emoções e pensamentos), assim como em relação ao ambiente externo (realização de novas atividades, retomada de antigos projetos, ampliação de relacionamentos sociais e afetivos).

$\mathrm{Na}$ literatura constata-se que a ausência de um dos cônjuges na vida dos filhos pode influenciar negativamente a percepção e a autoestima e contribuir para a construção de uma auto-imagem ruim, para o surgimento de ansiedade, para um desenvolvimento instável e para dificuldades em controlar a agressividade, a impulsividade, e sentimentos depressivos. Diante da separação conjugal muitos filhos não apresentam problemas comportamentais, enquanto outros os apresentam.

No grupoatendido, os filhos avaliaram como ruim a separação pela ausência de um dos pais, o que gerou neles alterações quanto aos padrões alimentares, somatizações, agressividade, irritabilidade sem motivo aparente e dificuldades na aceitação de novos parceiros dos pais. 
Quadro 6. Aspectos comportamentais dos sujeitos referentes ao "desempenho acadêmico."(")

\begin{tabular}{|c|c|c|}
\hline SUJEITOS & $\begin{array}{l}\text { COMPORTAMENTOS } \\
\text { PRÉ-INTERVENÇÄO }\end{array}$ & $\begin{array}{l}\text { COMPORTAMENTOS } \\
\text { PÓS-INTERVENÇÃO }\end{array}$ \\
\hline S. & $\begin{array}{l}\text { - Realizou curso profissionalizante } \\
\text { (cabeleira) } \\
\text { - Estudante do curso de Letras da } \\
\text { Universidade de Londrina por } \\
\text { sugestão do ex-marido } \\
\text { - Insatisfaçăo em relação ao curso } \\
\text { de Letras }\end{array}$ & - Ocurso de Letras passou a servalorizado \\
\hline L. & $\begin{array}{l}\text { - Notas boas no colégio (atribuía isto } \\
\text { à presença do pai) } \\
\text { - Participava de aulas no Kumon }\end{array}$ & - As notas decaíram (ausência do pai) \\
\hline $\mathrm{T}$. & $\begin{array}{l}\text { - Curso profissionalizante (manicure) } \\
\text { - Exigente quanto às notas do filho } \\
\text { - Preocupaçäo quanto à freqüência } \\
\text { do filho (E.) na escola }\end{array}$ & $\begin{array}{l}\text { - Percepcăo das causas que mantinham } \\
\text { o comportamento de E. năo ir à escola }\end{array}$ \\
\hline E. & $\begin{array}{l}\text { - Gosta de estudar } \\
\text { - Näo quer ir à escola } \\
\text { - Está quase reprovando por falta }\end{array}$ & $\begin{array}{l}\text { - Com a participação do pai houve } \\
\text { aumento na frequência de ir à escola }\end{array}$ \\
\hline c. & $\begin{array}{l}\text { - Professor universitário com titu- } \\
\text { laçăo de Doutor } \\
\text { - Exigente e disciplinado em relação } \\
\text { aos seus estudos }\end{array}$ & - Idem à pré-intervenção \\
\hline D. & $\begin{array}{l}\text { - Notas baixas } \\
\text { - Suspeita de reprovação } \\
\text { - Queixas da escola em relação a } \\
\text { disciplina }\end{array}$ & $\begin{array}{l}\text { - Esforço para tirar notas altas } \\
\text { - Aprovação do ano letivo }\end{array}$ \\
\hline
\end{tabular}

(") Dados coletados dos instrumentos e das verbalizaçōes dos encontros.

Notou-se que, quando os pais que não detêm a guarda dos filhos encontram-se ausentes, seus filhos apresentam alterações no rendimento escolar, que se refletem em notas baixas, queda na freqüência às aulas.

Isto foi corroborado pelo que enfatizam Teyber e Hoffman, 1987 (apud Moraes,1997),os quais acentuaram que a ausência de um dos ex-cônjuges pode gerar nos filhos o rebaixamento da auto-estima, que acaba refletindo na depressão, no desempenho acadêmico pobre e nas dificuldades dos relacionamentos interpessoais.

Ao final dos atendimentos, em relação aos aspectos positivos e negativos da separação, constatou-se uma melhora na participante $\mathrm{S}$, a qual afirmou estar se comportando de acordo com suas próprias necessidades e interesses e tomando decisões, como, por exemplo, retomar os estudos e tirar sua carteira de motorista. Quanto aos outros participantes, detectaram-se tentativas de manutenção de relacionamentos mais amigáveis com os ex-cônjuges, assim como o estabelecimento de diálogo e interações positivas em situações relativas à convivência e educação dos filhos, de um modo geral.

Pelo relato dos filhos, percebeu-se que os pais que não detêm a guarda são avaliados por eles como bons, pois, pelo contato restrito no relacionamento, acabam sendo mais permissi- 
vos, ao contrário dos pais que detêm a guarda, os quais assumem uma postura de imposição de leis e normas (regras), atitudes estas que requerem disciplina e por isso acabam sendo avaliados negativamente.

Isto pôde ser notado nos atendimentos iniciais ao grupo de pais, sendo que estes estavam certos de que os seus comportamentos eram avaliados negativamente, porém nãopercebiam que o fato de privar os filhos do contato com o ex-cônjuge contribuía para esta avaliação. Após a intervenção, os pais notaram que ao colocarem-se os filhos em contato com a realidade dos ex-cônjuges, desmistificaram-se as fantasias de que seria melhor morar com eles. Ao entrar em contato com estas contingências, os filhos perceberam que os outros genitores também Ihes colocavam normas e regras e, além disso, depararam-se com outras privações, como por exemplo, a contínua ausência desses pais que não mudaram sua rotina em função dos filhos.

Isto pôde ser encontrado na verbalização do participante D: "Fui morar com a minha mãe, e foi chato, ela trabalhava o dia inteiro... Eu até quis pular da janela, e ela não deu bola... $E$ também eu não gosto do cara que mora com ela, ele é muito chato... É melhor morar com meu pai..."(sic)

Quanto ao relacionamento social ocorreram modificações notórias nos padrões de comportamento dos pais e filhos, e no relacionamento entre os mesmos, sendo que os pais tornaram- se mais receptivos aos feedbacks do grupo, o que pode ter contribuído para que os filhos participassem melhor de atividades grupais. Da mesma forma que esta mudança ocorreu no grupo e foi percebida pelos terapeutas, acreditase que ela possa ter se generalizado para o ambiente natural dos participantes, e que seriam uma das variáveis importantes para a modificação nos padrões comportamentais dos filhos. Isto pôde ser observado no relato do participante Lque no início dos atendimentos verbalizava que a mãe não tinha qualidades e tentava esconder dela suas opiniões. Ao final dos encontros, sua percepção em relação a ela modificou-se, conforme o diálogo abaixo: tênis...

L - "Ah! Minha mãe não deixava sujar o

T - E agora?

L - Agora não pega tanto no meu pé...

$\mathrm{T}$ - $\mathrm{E}$ o que mais está legal?

L - Ela faz um macarrão gostoso e tá levando a gente para passear mais.

Em relação ao participante E, pôde-se observar que ele começou a perceber e a reagir ao afastamento do pai, o que pode ter contribuído para o seu isolamento no grupo. Esta percepção pode ter sido acarretada pela mudança do comportamento da mãe, a qual poupava-o de entrar em contato com esta realidade. Segundo Hess e Câmara,1979(apud Moraes, 1997), o medo de perder o contato com o pai, que está indo embora, é o principal fator que contribui para o desajuste causado pelo divórcio. As conseqüências emocionais advindas dessa situação para os filhos, como depressão, raiva, ansiedade e isolamento são bem severas.

Quando foi convocada uma sessão de orientação a pais que não detêm a guarda, os terapeutas notaram a ausência de um deles que mesmosecomprometendoavir, nãocompareceu.

Durante o processo grupal a auto-imagem de cada participante apresentou melhoras, os pais passaram a tomar atitudes que antes não tomavam, como, por exemplo, cuidar da própria aparência, permitir-se novos relacionamentos, bem como aceitar erros. Estas mudanças também foram percebidas nos filhos, quando 0 participante $L$ modificou as suas percepções quanto a se achar "feio e burro" e o participante $\mathrm{D}$ que passou a perceber-se como mais "autoconfiante".

Além dos resultados positivos apresentados, os terapeutas também encontraram algumas dificuldades na realização deste trabalho. Nos encontros iniciais, observaram que os pais 
não discriminavam que as queixas sobre os comportamentos dos filhos, por eles trazidas, estavam relacionadas com situações determinadas pelo processo de separação, como, por exemplo, por terem sido abandonados pelos excônjuges e pelas dificuldades no relacionamento com os mesmos, o que acarretou desavenças, instabilidade emocional, indefinição de papéis, dentre outros. Isto fez com que muitos dos comportamentos por eles apresentados nos encontros, como, principalmente, não assumir erros e racionalizações, contribuíssem para que os terapeutas sentissem que suas colocações pareciam não produzir efeitos sobre os comportamentos deles.

Ao final dos encontros, esses comportamentos foram-se modificando, o que levou aos resultados anteriormente discutidos.

Em relação ao grupo de filhos, pode-se perceber que os mesmos tiveram dificuldades em falar dos sentimentos relacionados à separação, os quais eram evocados através de atividades propostas pelos terapeutas. Outras dificuldades encontradas pelos terapeutas no início dos atendimentos se referem à dispersividade do grupo e à agressividade entre eles, que foram analisadas como respostas de fuga de uma situação aversiva (falar sobre a separação). Ao serem trabalhadas estas dificuldades, pode-se perceber que os padrões de comportamento foram-semodificando, diminuindo o nível de agressão e aumentando a freqüência de verbalizações de sentimentos, sinalizando, assim, uma melhora no que se refereà expressividade emocional.

De forma geral, pode-se perceber que tanto para pais quanto para filhos, houve modificações significativas no que diz respeito ao desenvolvimento do autoconhecimento e da expressão de sentimentos, o que demonstra a efetividade das intervenções realizadas.

\section{REFERÊNCIAS BIBLIOGRÁFICAS}

GIUSTI, E. 1987.A arte de separar-se. Rio de Janeiro: Nova Fronteira.

GRYCH, J.H. \& FINCHAM, F.D. 1990. Marital Conflict and Children's Adjustment: A Cognitive-Contextual Framework. Psychological Bulletin, 108, (2).

HESS, R. D. \& CÂMARA, K. A. 1979. PostDivorce Family Relationship as Mediating Factors in the Consequences of Divorce for Children. Journal of Social Issues, 35(4), 79-96.

KASLOW \& SCHWARTZ. 1995. As dinâmicas do Divórcio. Campinas, Editoria PSI.

LIPP, M. \& MALAGRIS, L. 1995. Manejo do estresse. In: Psicoterapia Comportamental e Cognitiva. Campinas: Editorial Psy.

MALDONADO, M.T. 1987.Casamento: término e reconstrução. Petrópolis, Vozes.

MEYER, S. B. 1997. O Conceito de análise funcional. In: DELITTI, M. (org.) Sobre comportamento e cognição. VoL. II. São Paulo: Arbytes, p. 31-36.

MORAES, C. G. A, et al. 1997. Grupo de Apoio a Filhos de Pais Separados. Tese de Pós- Doutorado, Apresentado ao Instituto de Psicologia da Universidade de São Paulo, São Paulo.

TEYBER, E.\& HOFFMAN,C. D. 1987. Missing Fathers. Psychology Today.(apr).

TSCHANN, J. M. et al. 1989. Family Process and Children's functioning during divorce. Journal of Marriage and the Family, 51(2). 